\title{
ASO Visual Abstract: What To Do When Decompressive Gastrostomies and Jejunostomies Are Not Options? A Scoping Review of Transesophageal Gastrostomy Tubes for Advanced Malignancies
}

Clara Zhu, MD ${ }^{1}$, Rebecca Platoff, $\mathrm{MD}^{\mathbf{1}}$, Gaby Ghobrial, $\mathrm{MD}^{\mathbf{1}}$, Jackson Saddemi, $\mathbf{B A}^{\mathbf{1}}$, Taylor Evangelisti, $\mathbf{B A}^{\mathbf{1}}$, Emily Bucher, BA ${ }^{1}$, Benjamin Saracco, MLS $^{2}$, Amanda Adams, MLS ${ }^{2}$, Simran Kripalani, BS ${ }^{2}$, Umur Atabek, MD ${ }^{1}$, Francis R. Spitz, MD ${ }^{1}$, and Young Hong, MD, MPH ${ }^{1}$

${ }^{1}$ Department of Surgery, Cooper University Hospital, Camden, NJ; ${ }^{2}$ Cooper Medical School of Rowan University, Camden, NJ

A scoping review was performed of percutaneous transesophageal gastrostomy tubes (PTEG) for malignant bowel obstructions. Fourteen articles were included for final analysis (https://doi.org/10.1245/s10434-021-10667- x). PTEG had similar complication rates as gastrostomy tubes and improved symptom relief compared with nasogastric tubes.

What to do When Decompressive Gastrostomies and Jejunostomies are Not Options?

A Scoping Review of Transesophageal Gastrostomy Tubes for Advanced Malignancies

Malignant Bowel

Obstructions

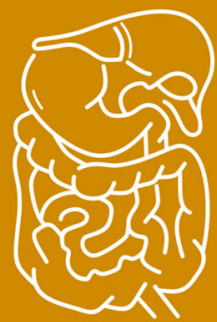

Transesophageal

Gastrostomy Tubes as an

Option for Palliation



56 Full-text reviews

15 Studies included 369 Patients

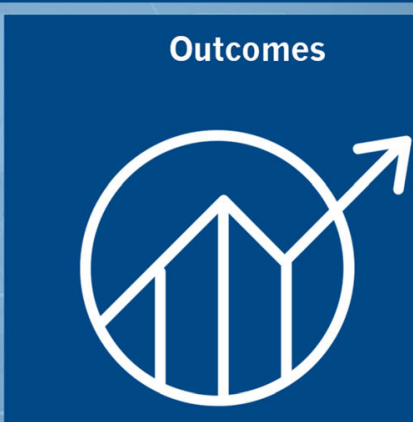

Improved quality of life $\mathbf{2 . 1 \%}$ Major complications $19.1 \%$ Minor complications
(C) Society of Surgical Oncology 2021

Published Online: 3 September 2021

Y. Hong, MD, MPH

e-mail: Hong-young@cooperhealth.edu
DISCLOSURES Clara Zhu, Rebecca Platoff, Gaby Ghobrial, Jackson Saddemi, Taylor Evangelisti, Emily Bucher, Benjamin Saracco, Amanda Adams, Simran Kripalani, Umur Atabek, Francis R. Spitz, and Young Hong have no disclosures to report.

Publisher's Note Springer Nature remains neutral with regard to jurisdictional claims in published maps and institutional affiliations. 